\title{
Desvelando o cotidiano dos cuidadores informais de idosos
}

\author{
Unveiling the routine of informal caregivers for the elderly \\ Revelando el cotidiano de los cuidadores informales de ancianos
}

\author{
Michel Patrick Fonseca Rocha', Maria Aparecida Vieira', Roseni Rosângela de Sena' \\ 'Universidade Estadual de Montes Claros. Departamento de Enfermagem. Montes Claros, MG \\ Kellog Foundation. Belo Horizonte. MG
}

Submissão: 30/07/2008

Aprovação: 15/1 1/2008

\section{RESUMO}

Este artigo objetivou descrever como os cuidadores informais de idosos interpretam e constroem o seu cotidiano. Estudo Qualitativo, descritivo-exploratório, tendo como orientação teórico-metodológica, a dialética. O instrumento de coleta de dados foi a entrevista individual, com cinco cuidadores de idosos dependentes em domicílios de um Programa Saúde da Família, em Montes Claros - Minas Gerais. Resultados evidenciaram situações adversas enfrentadas pelos cuidadores relacionadas ao sofrimento e sacrifícios na prestação dos cuidados e a falta de assistência para atender as necessidades do ser cuidado e do ser cuidador. Porém, exercem o cuidar com amor, carinho e dedicação, utilizando a fé e a espiritualidade como busca do equilíbrio biopsicossocial. Recomenda-se Que esses profissionais tenham um olhar respeitoso e cooperativo ao trabalho desses cuidadores.

Descritores: Cuidados domiciliares de saúde; Cuidadores; Assistência a idosos.

\section{ABSTRACT}

This article intends to describe how the informal caregivers interpret and build their daily routine. It is a Qualitative study using dialectics as the theoretical-methodological framework. The instrument for data colection was individual interviews with five caregivers for elderly in homes in the Family Health Program, in Montes Claros, Minas Gerais State, Brazil. The results demonstrated adverse situations faced by caregivers in terms of suffering and sacrifice in providing care and a lack of support meeting the needs of the caregivers and those receiving care. However, they provided care with love and dedication using faith and spirituality in search of biopsychosocial balance. It is recommended that health workers should have a respectful and cooperative approach to the work of these informal caregivers for the elderly.

Descriptors: Home nursing; Caregivers; Old age assistance.

\section{RESUMEN}

El propósito del presente artículo ha sido describir cómo los cuidadores informales de ancianos interpretan y construyen su rutina. Se trata de un estudio cualitativo, descriptivo y exploratorio, con orientación teórico-metodológica. La recogida de datos se realizó mediante entrevistas individuales a cinco cuidadores de personas mayores dependientes Que viven en domicilios incluidos en un Programa de Salud de la Familia de Montes Claros, Estado de Minas Gerais. Los resultados revelan que los cuidadores enfrentan situaciones hostiles Que tienen Que ver con sufrimiento y sacrificios en la prestación de los cuidados y con la falta de asistencia para atender a las necesidades del anciano y del cuidador. Pero, ejercen su tarea con amor, cariño y dedicación y, a través de la fe y de la espiritualidad, buscan su equilibrio biopsicosocial. Se aconseja Que el trabajo de estos profesionales sea considerado com respecto y cooperación.

Descriptores: Atención domiciliaria de salud; Cuidadores; Asistencia a los ancianos. 


\section{INTRODUÇÃO}

A população mundial está envelhecendo em ritmo acelerado, apresentando demandas e necessidades no campo da saúde e da assistência social. Nos últimos anos, cerca de um milhão de pessoas cruzaram a barreira dos 60 anos, a cada mês e em todo o mundo, provocando mudanças importantes na estrutura etária das populações em praticamente todos os países ${ }^{(1)}$.

Ainda Que a velhice não seja sinônimo de doença e dependência, o crescimento dessa população leva ao aumento do número de pessoas com debilidades físicas e emocionais e, em muitos casos, podem depender de um cuidador.

De acordo com Sanchéz ${ }^{(2)}$, a dependência pode ser considerada em três níveis: a dependência estruturada, resultante da circunstância cultural Que atribui valor ao ser humano em função do Que é e do Quanto produz; a dependência física Que decorre da incapacidade funcional, ou seja, a falta de condições para realizar as tarefas da vida diária em diferentes graus de severidade e a dependência comportamental, Que é socialmente induzida, pois advém do julgamento e das ações de outrem. A dependência da pessoa idosa ocorre Quando se torna incapaz de realizar as atividades da vida diária e, Quando isso acontece, um cuidador assume a função de apoio, por meio do cuidado Que pode ser permanente ou esporádico ${ }^{(3)}$.

Na maioria dos casos de pessoas idosas dependentes, a demanda por cuidados é assumida pela família e, em conseqüência, a necessidade freeüente de se recorrer à assistência social e de saúde para apoio aos familiares. O Sistema Público de Saúde do Brasil, entretanto, ainda não fornece o suporte adequado ao idoso Que adoece nem à família Que dele cuida ${ }^{(4)}$.

A atenção domiciliar surge como modelagem de atenção especialmente para idosos com doenças incapacitantes, dependentes do apoio de cuidadores. Essa modalidade de atenção é tão antiga Quanto os agrupamentos sociais mas tem se tornado mais visível com o envelhecimento da população e a reconfiguração do domicílio como "lócus do cuidado".

No contexto da atenção domiciliar, os cuidadores são, em sua maioria, informais; geralmente um integrante da família Que adota o papel de cuidador do idoso ou portador de enfermidade debilitante, assumindo assim a responsabilidade pela prestação de cuidados no domicílio ou em instituições Que oferecem atenção ao idoso.

Os cuidadores, profissionais ou não, realizam as mais variadas tarefas, cuidando e restabelecendo a Qualidade de vida do idoso ${ }^{(3)}$. São classificados, segundo Papaleo Neto(I), como cuidadores formais e informais.

Os cuidadores formais prestam cuidados no domicílio com remuneração e com poder decisório reduzido, cumprindo tarefas delegadas pela família ou pelos profissionais de saúde Que orientam o cuidado. São profissionais capacitados para o cuidado, contribuindo de forma significativa para a saúde das pessoas cuidadas. Esses cuidadores têm, em geral, formação de auxiliar ou técnico de enfermagem, com formação orientada para o cuidado em saúde dos portadores de patologia física ou mental, em função do atendimento de necessidades específicas ${ }^{(1)}$.

Os cuidadores informais são os familiares, amigos, vizinhos, membros de grupos religiosos e outras pessoas da comunidade.
São voluntários Que se dispõem, sem formação profissional específica, a cuidar de idosos, sendo Que a disponibilidade e a boa vontade são fatores preponderantes ${ }^{(5)}$.

O conhecimento do perfil dos cuidadores e de suas dificuldades no processo de cuidar permite, aos profissionais da saúde, planejar e implantar políticas e programas públicos de suporte social à família, voltados à realidade do cuidador. Isso porque o cuidador está em condições de sobrecarga de trabalho, o Que contribui para o adoecer e para o desenvolvimento de situações de conflito entre o cuidador e o idoso dependente ${ }^{(6)}$.

Em 19 de outubro de 2006, o Ministério da Saúde instituiu a Portaria $n^{\circ} 2.529$, Que regulamenta a Internação Domiciliar no âmbito do SUS. A internação domiciliar é definida por um conjunto de ações realizadas no domicílio, a pessoas clinicamente estáveis Que precisam de cuidados, mas Que não necessitam da internação hospitalar. O objetivo é o de proporcionar um atendimento humanizado Que promova maior autonomia da pessoa cuidada e de sua família( ${ }^{(7)}$.

O cuidador deverá também receber atenção a sua saúde pessoal, considerando-se que a atividade de cuidar de um adulto dependente é desgastante e implica em riscos à saúde do cuidador. Por conseguinte, a função de prevenir perdas e agravos à saúde abrangerá, igualmente, a pessoa do cuidador $^{(8)}$.

Esta pesquisa teve como objetivo compreender como os cuidadores informais de idosos enfrentam, no cotidiano, as situações de conflito, as tensões, os desgastes físicos e emocionais, as alterações de planos de vida, o isolamento social, a sobrecarga de trabalho, os dilemas e o estresse, em um território do Programa de Saúde da Família (PSF), em Montes Claros - MG.

Segundo Santos ${ }^{(5)}$ é primordial Que se ofereçam condições de infra-estrutura e de suporte para Que os familiares possam efetivamente exercer o papel de cuidadores informais. É necessário Que, além de se conhecerem as necessidades de cuidado da pessoa dependente, também se conheça a situação dessas famílias: suas demandas, suas crenças, seus valores e suas práticas sócio-culturais.

Espera-se Que os profissionais de saúde do Programa Saúde da Família, do município de Montes Claros-MG, onde foram coletados os dados deste estudo, sintam-se instigados a voltar sua atenção à realidade enfrentada pelos cuidadores informais Que, muitas vezes, são ignorados pela sociedade e afastados das discussões familiares. Assim, ao analisar os desafios vividos pelo cuidador, os profissionais da saúde poderão participar ativamente da assistência ao cuidador de idosos, valorizando-o e dando-lhe suporte nos cuidados, oferecendo capacitação a ele e a sua família sobre como lidar com situações potencialmente geradoras de conflitos e tensões a fim de contribuir para a Qualidade de vida do ser cuidado, cuidador e a família no domicílio.

Espera-se Que os resultados desta pesquisa tornem visíveis os significados da vivência desses cuidadores informais de idosos.

\section{METODOLOGIA}

O presente estudo optou pela abordagem Qualitativa para captar o cotidiano dos cuidadores de idosos. Segundo Triviños ${ }^{(9)}$ essa abordagem responde a Questionamentos extremamente particulares, além de oferecer a possibilidade de conhecer pela percepção, vivência, experiência de vida e reflexão a realidade, afim de 
transformá-la. Para o autor, a pesQuisa Qualitativa parte da descrição dos fenômenos, procurando captar não só a sua aparência como também a sua essência. Busca as causas, a origem, as relações, as mudanças e suas conseQüências para a vida humana.

Compreende, ainda, as representações sociais na vivência das relações objetivas dos cuidadores de idosos de um território de saúde em Montes Claros, atribuindo-Ihes significado no universo dos motivos, aspirações, crenças e valores e na intencionalidade ligada aos atos, às relações e às estruturas sociais ${ }^{(10)}$. Essa escolha justifica-se, também, pela concepção de Que a abordagem Qualitativa é capaz de captar a realidade concreta e subjetiva da interação dialógica e dialética entre cenários, sujeitos e pesquisadores.

Nesse sentido, este estudo foi orientado pelo referencial teóricometodológico da dialética Que, para Gadotti ${ }^{(1)}$, contempla os fenômenos como um todo coerente, no Qual os objetos, atores, e os próprios fenômenos condicionam-se reciprocamente, e interagem entre si. Segundo Minayo ${ }^{(10)}$, a dialética representa o caminho teórico Que aponta a dinâmica do real na sociedade, contextualizando o processo histórico com seu dinamismo, provisoriedade e transformação, buscando apreender a prática social empírica dos indivíduos na sociedade e realizar a crítica das ideologias do binômio sujeito/objeto, ambos históricos e comprometidos com os interesses e as lutas sociais de seu tempo.

A opção por essa orientação teórico-metodológica permitiu uma aproximação da realidade objetiva a partir dos significados sobre ser cuidador de idosos dependentes, revelando as contradições inerentes ao cotidiano dos cuidadores.

Trata-se também de uma pesquisa descritiva, que "descreve um fenômeno ou situação, mediante um estudo realizado em determinado contexto espacial e temporal"(12). Esta investigação foi realizada nos domicílios dos cuidadores informais e locais de residência dos idosos dependentes sob seus cuidados, localizados em um território do Programa de Saúde da Família, em Montes Claros - Minas Gerais. Os sujeitos deste estudo foram cinco cuidadores informais de idosos dependentes, dos Quais três são mulheres e dois são homens, domiciliados na área adscrita de uma equipe do Programa de Saúde da Família (PSF).

A seleção dos cuidadores ocorreu por meio de amostragem não-probabilística, optando-se por uma amostra por acessibilidade, onde o elemento pesquisado é auto-selecionado ou selecionado por estar disponível no local e no momento em Que a coleta é realizada ${ }^{(12)}$.

Buscando atingir o objetivo proposto, foram utilizados, como instrumentos de coleta de dados, a pesquisa bibliográfica e a entrevista individual com roteiro semi-estruturado.

As entrevistas individuais foram realizadas nos domicílios dos cuidadores e dos idosos dependentes, em condições adeQuadas de comodidade e privacidade, proporcionando a espontaneidade necessária. Essa modalidade de coleta de dados permite que o pesquisador esteja presente no momento da entrevista e que o sujeito da pesquisa tenha a possibilidade de responder aos Questionamentos com liberdade, enriQuecendo a investigação ${ }^{(13)}$.

Para o registro das entrevistas, foi utilizada a gravação das informações fornecidas pelos participantes. O uso do gravador dá ao pesQuisador a certeza de Que obterá a reprodução fiel e integral da fala, evitando-se, assim, o risco de interpretações equivocadas ${ }^{(14)}$. Permite, também, Que o pesquisador fique atento à fala do entrevistado, intervindo Quando se fizer necessário. Esclareceu-se aos entrevistados Que não se preocupassem em dar respostas consideradas corretas, pois o Que se deseja é captar a sua maneira de pensar e perceber o tema abordado ${ }^{(13)}$.

Anteriormente à entrevista foi realizado o pré-teste com a intenção de assegurar a validade e a precisão das Questões norteadoras da entrevista. O cuidador entrevistado no pré-teste não foi incluído no estudo(13).

O Projeto de Pesquisa foi aprovado pelo Comitê de Ética em Pesquisa da Universidade Estadual de Montes Claros que emitiu o Parecer Consubstanciado - Processo n²94, de 17 de março de 2006. Foram observadas as orientações da Resolução 196/96 do Conselho Nacional de Saúde. Também foi solicitada, à Gerência do Programa de Saúde da Família, autorização para a realização deste estudo.

Os entrevistados foram informados Quanto aos objetivos da peseuisa, à autonomia individual, à privacidade, à confidencialidade das informações e de Que os resultados seriam utilizados exclusivamente para fins científicos. Após os esclarecimentos, assinaram o Termo de Consentimento Livre e Esclarecido. Para se garantir o anonimato dos sujeitos, foram utilizados números de identificação e as codificações estão presentes na análise dos dados.

A análise dos dados empíricos foi organizada segundo a técnica de análise do discurso na Qual, segundo Minayo ${ }^{(10)}$, os dados são classificados a partir de um Questionamento com base na fundamentação teórica e elaboradas as categorias Que se referem a um conceito Que abrangem elementos ou aspectos com características comuns ou Que se relacionam entre si. Dessa forma, constituíram-se três categorias empíricas: tornando-se um ser dependente de cuidados; dificuldades do ser cuidador: aprendizagem e superação; as estratégias do cuidar de idosos dependentes.

\section{RESULTADOS E DISCUSSÃO}

\section{Tornando-se um Ser Dependente de Cuidados}

Segundo Elias ${ }^{(15)}$, o envelhecimento é um processo dinâmico e progressivo no Qual ocorrem modificações tanto morfológicas Quanto funcionais, bioQuímicas e psicológicas que determinam a diminuição de adaptação do indivíduo ao meio-ambiente, ocasionando maior vulnerabilidade e maior incidência de processos patológicos. Para Carvalho Filho ${ }^{(16)}$, o envelhecer é aquele período da vida Que sucede à fase de maturidade, caracterizado por declínio das funções orgânicas Que acarreta maior susceptibilidade ao surgimento de doenças, terminando por levar o idoso à morte. Essa diminuição da capacidade funcional é linear, em função do tempo. O indivíduo perde progressivamente sua capacidade ocorrendo a necessidade de adaptações a uma nova situação, seja física, emocional ou econômico-social. O Brasil, talvez em decorrência do sistema de saúde pública, não se encontra preparado para fornecer o suporte à população Que envelhece nem a sua família $^{(4)}$. Os relatos a seguir contribuem com essa análise:

O tempo foi passando e ele foi ficando mais ruim, não tava conseguindo nem andar né! Eu cuidei dele, fieuei carregando ele um ano e meio [...]. Nas minhas contas tem I I anos Que ele é doente $(\mathrm{Cl})$. 
Ela tem 96 anos, tá aí firme, desse jeito, sofrendo, pode ser Que daQui umas curtas horas... Mas ainda demora muito, ainda vive [...] e pior é que não enxerga Quase nada mais, escuta, mas não sabe Quem é Que tá falando (C5).

Para Carvalho Filho ${ }^{(16)}$ o envelhecer é um processo seeüencial da vida humana, individual, cumulativo, irreversível, não-patológico, de deterioração de um organismo maduro, próprio a todos os membros de uma espécie. O tempo torna-os menos capazes de fazer frente ao estresse do meio ambiente e, portanto, aumenta sua possibilidade de morte ${ }^{(17)}$. O discurso a seguir revela tal situação:

Ele vai ficar paraplégico, e é uma doença que infelizmente a medicina ainda não descobriu um remédio para combater, só pode fazer pra resolver, seria uma fisioterapia, mas no caso dele já passou muito tempo [...] Hoje já está da cintura pra cima, ele sente muita dor nos braços, no corpo todo, do pescoço pra baixo ele não sente nada, tudo dormente, ele coça, ele machuca, não vê e não sente nada, só vê Quando está sangrando, né! Ou então, Quando eu vou dar o banho nele, eu vejo as pernas machucadas, e fora isso tem as fraeuezas nos ossos, pega gripe com muita facilidade, sente dor demais [...] (Cl).

A presença de imobilidade, instabilidade, incontinência, insuficiência cerebral e iatrogenia implicam em prejuízo para a independência funcional, impedindo a pessoa de atender suficientemente as necessidades da vida diária como alimentares, higiênicas e sociais $^{(18)}$, como expresso a seguir:

Dou os medicamentos que o médico passou, é tudo certinho, e a comida também, faço a sopinha e coloco na boca dele, ele tá com uma tremura na mão Que não consegue segurar nada... onde ele tiver faz xixi, cocô na roupa [...] chega na sala e faz cocô, aí eu tenho Que pegar a mangueira, dá um banho nele, ensaboar, mas é bobagem dar banho nele, Que daí um instante ele tá todo mijado Que nem criança, tá mijado! Fazia cocô na roupa! Você precisa ver como que é... Ele foi curado, voltou pra casa fortezinho, mas parecia que estava assim meio abestaiado [...] mas aí depois ele ficou mal mesmo! Ficou abestaiado mesmo! Babando! Assim sem saber onde ele tava! Fazia xixi no meio da casa! Pra banhar a gente banhava, foi aí ele arruinou de vez... Parecia Que ia morrer (C2).

Assim, a família passa a ter uma co-responsabilidade, no momento em Que ocorrem alterações nas condições de vida de um dos seus integrantes, principalmente no caso de adoecimento. Os familiares são os primeiros a reconhecer essas necessidades e a oferecer os cuidados essenciais aos idosos Que se tornam dependentes. Estes também irão necessitar de cuidados $^{(19)}$.

Uma grande dificuldade no processo de cuidar está em romper com os valores adeuiridos desde a infância do cuidador: o pudor em invadir a privacidade e a intimidade do outro, Que é seu pai, a sua mãe, o sogro. Até então era proibido ou não era aceito como natural $^{(20)}$. Isso está presente nos discursos dos cuidadores entrevistados:

[... I nada disso minha filha, pode ajudar aí, seu pai é um homem igual outro Qualquer, vamos juntar nós duas e banhar, não tem problema não, tiramos a roupa dele! Demos o banho! Enxugamos! Vestimos a roupa! E levamos pro hospital... (C2).

[...] já tentei dar banho, mas ela não Quer, ela tem vergonha, fica aí suja, toma é as prestações (dia sim, dia não), [... tem um preconceito danado (C5).

Dar o banho, fazer a toalete e vestir um idoso podem representar muito mais ônus para o cuidador, visto Que a falta de cooperação e as alterações de comportamento do idoso acentuam-se nessas situações e geram muita angústia. O cuidado prestado pelo cuidador informal é marcado pelo despreparo psicológico e emocional Que pode gerar, em várias ocasiões, conflito, insatisfação, insegurança e sensação de desespero ${ }^{(19)}$. Assim, o cuidar pode causar desgaste físico e emocional, pois muita energia vital é cedida para Que o cuidado passe a alimentar, educar e cultivar o crescimento do outro $^{(21)}$.

\section{Dificuldades do Ser Cuidador: Aprendizagem e Superação}

Diversos são os desafios Que se apresentam no cotidiano do cuidador tais como a dificuldade para lidar com os Quadros de agitação e de agressividade do ser cuidado, com a deambulação constante e especialmente noturna, provocada pelas alterações nos hábitos de sono e repouso, com os esquecimentos, a repetitividade, a teimosia e as solicitações constantes, com a falta de etiqueta à mesa e no trato social e com os comportamentos bizarros, como, por exemplo, despir-se ${ }^{(16)}$. O mais difícil no processo de cuidar está nesse convívio diário com os distúrbios de comportamento apresentados pelos idosos, como expresso nos discursos:

[...] tem que ficar de cima, tomou o café? - não tomei não porque não tomou o café ainda? Porque às vezes tem Que tratar Que nem criança! - Quero tomar não - não, tem Que tomar! [...] Deus me curou - tudo bem, Deus te curou, mas deixou os médicos aqui pra isso, tem que tomar. Aí daqui a pouco - Ah! Então vou tomar - entendeu? Parece uma criancinha (C4).

A gente pergunta: Qué chá? Não Quer, daQui a pouco, cinco minutos, já Quer, só dá tempo de esfriar na panela, tem que tornar esquentar de novo, café com leite, biscoito, tá sempre aí, toda hora (C5).

As principais dificuldades encontradas ao lidar com o idoso referem-se ao enfrentamento da teimosia de sua resistência em seguir as orientações, ficando o cuidador freeüentemente abalado emocional, psíquica e fisicamente ${ }^{(22)}$. A maneira negativa como o idoso trata o cuidador pode revelar a não-aceitação da relação de dependência ${ }^{(23)}$.

O cuidador informal expõe-se a uma série de fatores estressantes como o peso das tarefas e as doenças advindas das exigências do trabalho e das características do idoso. Além disso, faltam-lhe informações. Falta-lhe apoio físico, psicológico e financeiro para enfrentar a rotina ${ }^{(8)}$, conforme indicam os depoimentos:

[...] Ah... Tem dia Que a gente tá nervoso, tem dia Que dá vontade de chutar tudo, tem hora que fico meio nervoso, o 
povo fala muita coisa com a gente, pressão sobe, mas é nervoso Que eu passo de vez em Quando, mas tem Que fazer né, não pode judiar né! Tem que fazer conforme até o dia que Deus Quiser (C5).

[...] ela é tia de minha mãe, e meu marido fala assim: você não tem Que fazer isso não! Quem tem Que fazer isso é os filhos dela! Aí eu falo: não tem nada a ver não! Não pode é deixar ela aí desse jeito, tem Que cuidar! É como se fosse um filho mesmo, porQue senão, ninguém faz, e fica essa coisa aí acabando. Ah! Mas cadê os filhos dela? - Ah! Os filho dela não importa com ela, ninguém não Quer nem saber como ela tá (C4).

Em relação ao discurso de $\mathrm{C} 4$, Elsen ${ }^{(24)}$ afirma Que o fato de um familiar assumir o cuidado pode representar a falta de apoio e de comunicação entre os membros da família o Que, na prática, pode afetar a saúde familiar.

Para Scazufca ${ }^{(25)}$, as dificuldades das pessoas cuidadas em executar atividades da vida diária podem causar problemas na casa e estresse nos familiares e, por isso, têm sido apontadas como geradoras do sentimento de sobrecarga nos cuidadores informais.

As atividades Que necessitam de espaço físico são as Que causam maior dificuldade para o cuidador porque, para cuidar de um adulto dependente, é necessário ter condições físicas, espaço adeoüado e equipamentos que ajudam nas tarefas pesadas, como a locomoção e Que permitam ao cuidador recuperar-se rapidamente, por exemplo, de uma noite mal dormida ${ }^{(20)}$. Essas dificuldades estão expressas nos seguintes relatos:

[...] pessoa destrenada pra mexer com esse tipo de coisa não é fácil não! Pior é Que sou sozinho [...] ela é pesada também [...] se ela cair, dá um trabalho danado pra levantar, pesada! Gente fraca que nem eu (problema físico) é muito difíil mexer com outra só (C5).

Aí eu peguei ele, pelejei pra colocar ele na cama sozinha e nada! Pelejava, ele escorregava, o corpo dele pesa demais né! (C2).

Para Alvarez ${ }^{(26)}$, a habilidade e o conhecimento da atividade de cuidar são construídos na prática diária, na Qual a família aprende com os seus erros e acertos, sendo Que a falta de preparo para o cuidado gera, uma ansiedade Que é substituída por segurança a partir do momento em Que consegue organizar-se. Essa situação, porém, não é estável, posto Que o estresse leva uma mesma pessoa a passar por experiências ambíguas em relação ao mesmo evento.

O cuidador informal sofre, se fere, perde, se entrega e se desgasta. Ocorre a desestruturação de sua vida ${ }^{(27)}$. Nesse sentido, o cuidar de um idoso dependente exige muito mais Que tempo, carinho, disponibilidade, abnegação de uma "outra vida"(3).

Segundo Néri ${ }^{28)}$, as tarefas evolutivas Que correspondem ao desempenho de papéis sociais, ao exercício de atividades e à exibição de competências, crenças e valores, transcorrem de modo imprevisto, como acidentes, doenças e perdas Que são vividas como crises, pelo fato de as pessoas não estarem preparadas para enfrentá-las. Os discursos dos cuidadores informais mostram suas dificuldades no enfrentamento dessas crises:
PorQue Quando é com uma criança aí você tem aquela coisa! Todo um cuidado e no caso dela, ela é uma senhora, é mais pesada, às vezes ela fica com vergonha da gente ficar mexendo nela, não Quer deixar, então tem Que arrancar a roupa, ficar nua na frente nossa, né! l... água ela tem Que tomar de duas vezes, ela treme a mão toda e derrama a água na roupa, a comida também (C4).

Qualquer um sabe Que o sofrimento não é pouco né! É difícil, muito difícil... (C2).

[...] mas moço... mãe tava era morrendo! É você Que não vê, eu tô vendo, tô aqui, é eu é que sei! Mãe não tava comendo nada (C5).

Os cuidadores apresentam essas dificuldades principalmente porQue convivem com as limitações. Sentem-se envolvidos emocionalmente na situação. Além de desempenhar novos papéis e tarefas associadas ao problema do idoso cuidado no domicílio, os cuidadores informais freqüentemente relatam um sentimento de sobrecarga e também problemas relacionados à sua saúde mental, como depressão e ansiedade ${ }^{(21)}$ :

Às vezes as pessoas preocupam com ele, mas não sabem o Que está passando na minha cabeça, não tem aquela atenção de chegar, ô filha, vamos conversar um pouQuinho, tinha vez Que eu ia para o banheiro e ia chorando, minha cabeça danava a doer. Uma vez o Dr. falou Que esse problema meu é cansaço mental, porQue Quem cuida de doente, ele sofre mais que o doente, ele tá sofrendo com aquela pessoa ali e não pode fazer nada, né! E não acha uma pessoa para poder partilhar com ele o Que passa na cabeça dele (CI).

E nesse movimento os cuidadores vão construindo seu cotidiano de co-responsáveis pelo ser cuidado em situações adversas e de alta imprevisibilidade.

As dificuldades vivenciadas pelos cuidadores no domicílio são a falta de transporte para os serviços de saúde, a resistência do idoso aos cuidados, o ambiente inadequado, a "falta de conhecimento" para prestar os cuidados e para distinguir entre uma necessidade orgânica e uma necessidade emocional por carência afetiva e a "falta de paciência"(29), evidenciadas no conjunto discursivo:

[...] aí Quando ela passa mal [...] assim... É uma loucura né! Porque tem Que sair pra procurar um carro prá levar pro hospital, vaga também não tem! Tem muita gente na frente (C4).

[...] eu tenho Que arranjar um carro pra levar ela no hospital, QualQuer coisa Que ela precisa tem que levar, não tem jeito, é o jeito, é o jeito (C5).

[...] às vezes tenho né! PorQue pesa muito, né! E às vezes ele ficava assim sem Querer Que a gente cuidava dele, ficava mexendo esperneando pra gente não mexer nele, teve um dia aí Que eu fieuei com dor no corpo, nas perna e nos braços porQue eu não agüentava mexer com ele, minha filha trabalha, eu fico aqui 
sozinha com ele [...] (C2).

Para Creutzberg ${ }^{(30)}$ o aumento do grau de dependência do idoso gera para o cuidador dificuldade na mobilidade. As dificuldades vêm desde a falta de condicionamento físico para realizar a movimentação até o medo de não conseguir realizá-la de forma adequada.

Os cuidadores relatam dificuldades financeiras, de moradia, de falta de assistência à saúde e a falta de uma rede de suporte social ${ }^{(5)}$ :

[...] tenho um pouco de dificuldade nesse ponto, porque às vezes dá vontade de comer uma carne e não tem dinheiro pra comprar, isso dói, porque é triste ver aquela pessoa que precisa de tanta coisa e você dá vontade de comprar e não dá, né! Dói, dói muito... (Cl).

[...] e também tá gastando numa remedaiada, a caixinha de remédio é 33 reais, ele toma duas por mês, só de um que é o da cabeça, e toma outro do estômago Que é 130 comprimidos por mês, também tudo comprado, e outro de pressão, só um Que é manipulado, 70 comprimidos, dá uns trinta e poucos reais, mas mesmo assim é caro né! A gente tirar da onde não tem (risos) fica muito caro, mas vai levando... (C2).

Uma das principais dificuldades apontadas por Creutzberg ${ }^{(30)}$ é a escassez de recursos financeiros. A falta de dinheiro pode gerar angústia no cuidador Que Quer dar o melhor para o seu parente idoso.

Santos ${ }^{(5)}$ relata Que há, ainda, outros problemas decorrentes do ato de cuidar, como o estresse secundário à atividade do cuidado, a sobrecarga provocada pelo exercício da função de cuidador e a prevalência de depressão, ocasionando alterações na Qualidade de vida ou de seu bem-estar físico, psicológico e social

Scazufca ${ }^{(25)}$ acrescenta Que a maneira como a pessoa percebe uma situação contribui para a sua habilidade em mobilizar formas efetivas para se adaptar a ela. O cuidador informal, geralmente lida com a perspectiva de um maior isolamento social, falta de tempo para si próprio e para o contato com a família e os amigos, possíveis interrupções na carreira profissional, gastos excessivos e falta de tempo para lazer. Os relatos, a seguir, corroboram essas afirmações:

[...] Diversão minha já acabou tem é tempo, sábado, domingo e segunda pra mim é uma coisa só, minha vida mudou demais, acabou depois que ela veio prá cá, acabou, agora não posso sair mais pra canto nenhum, não agüento mais, e eu também fieuei desse jeito, é difícil demais, emprego não arranja mais [...] (C5).

Nunca viaja todo mundo junto em função dela, tem Que ficar de olho, se minha mãe sai, eu fico, se eu saio, fica minha mãe, meu marido $(\mathrm{C} 4)$.

[...] e sempre tem que ficar uma pessoa aqui com ela, Quando eu não tô, meu irmão tá (C3).

[...] Quando ele trabalhava, né! De vez em Quando eu saía, no domingo eu ia a missa, mas depois que ele ficou assim, eu fiQuei sem tempo prá sair, porQue eu não vejo, eu não sinto vontade de sair, e por exemplo: deixar ele aqui? E se eu levar ele? Ele também não gosta de sair mais, então fico aQui com ele [...] ele depende de mim, o problema dele foi agravando então eu preferi ficar aqui com ele. Não posso trabalhar porQue tenho Que cuidar dele $(\mathrm{Cl})$.

O cuidador de idosos dependentes é aquele que põe a necessidade do outro em primeiro lugar e, pressionado por necessidades imediatas, esquece-se de si mesmo ${ }^{(31)}$, porque o cuidado constante toma praticamente todo o seu tempo, as suas forças, o seu lazer e até suas emoções. Assim, a rotina diária Que determina os afazeres do cuidador exclui a sua vontade ou preferência. Abre mão de sua vida para aQuele de Quem está cuidando ${ }^{(23)}$.

\section{As Estratégias do Cuidar de Idosos Dependentes}

As crenças em um ser superior, a fé, a espiritualidade e as práticas religiosas são percebidas pelos cuidadores como estratégias muito eficazes de enfrentamento da sobrecarga do cuidado, da angústia, do estresse e da depressão decorrentes do processo de cuidar $^{(5)}$

Para Goldstein ${ }^{(32)}$, as crenças existenciais, espirituais ou religiosas não só auxiliam no enfrentamento das dificuldades mas dão sentido à vida, à velhice, à dependência e ao cuidar. Contribuem também para Que os eventos sejam interpretados de forma mais positiva e enfrentados de forma mais eficaz:

[...] O caso do seu esposo é grave, tem que conformar, pedir à Deus, e nós estamos suspeitando de câncer, e é câncer maligno, e eu falei: mas tem um médico que cura, né! Deus é maior, Deus vai tocar a mão aí e ele vai ser curado, em nome de Jesus. Neste momento eu clamei ao Senhor: meu Pai socorre aqui, segura na mão do meu esposo, não deixa ele morrer assim [...] tá vendo como Deus é bom, né! Deus é maravilhoso, toda família é muito religiosa, não só eu mas toda a Igreja estava orando por ele [...] as coisas que é permitido por Deus, a gente tem Que conformar porQue Deus, ele não põe a doença não, mas ele permite, né! Às vezes a mão de Deus pesa sobre a gente, só Deus sabe (C2).

Eu me sinto bem, dar uma tranqüilidade, né! Tem que buscar forças naquele que é maior [... então eu encaro o meu problema, porque dá trabalho! E mau conselho todo mundo dá, agora... Eu sigo o meu coração e agradeço a Deus também por isso, porque eu não imagino, eu morro de medo de chegar o dia de levantar, eu olhar pra ele e ele estiver morto do meu lado, eu não aceito, eu brigo comigo mesma, eu Quero Que ele vive! Nós dois assim bem velhinhos (C3).

Outro aspecto importante da religiosidade é a possibilidade de o cuidador e de seus familiares receberem mais suportes espirituais, emocionais, sociais e até materiais, Quando participam ativamente de comunidades religiosas organizadas Que se preocupam com seus membros ${ }^{(5)}$. A religiosidade e a espiritualidade não só funcionam como estratégias de enfrentamento ao estresse e à 
depressão, como também auxiliam na subsistência, no bem-estar psicológico e no processo de reintegração social desses cuidadores. A convivência com os demais membros de sua igreja e o suporte recebido fortalece-os e dá novo sentido para suas vidas. Nessas circunstâncias, a religiosidade e a espiritualidade funcionam como fatores explicativos e protetores para a saúde e para a estabilidade emocional dos cuidadores:

[...] Ah... Ontem mesmo tive Que ir na igreja, domingo não posso faltar! - Mas você vai me deixar só? Assiste aqui na televisão. - Eu falo: não! Tem Que ir lá (C5).

O cuidar é mais que um ato; é uma atitude. Representa uma atitude de ocupação, de preocupação, de responsabilização e de envolvimento afetivo com o outro. O cuidado perpassa toda a existência humana com ressonâncias em diversas atitudes importantes ${ }^{(33)}$.

Alvarez $^{(26)}$ afirma Que a percepção do cuidador de estar se sacrificando gera um sentimento de estar cumprindo com sua obrigação, o que torna o cuidado gratificante. Cuidar do seu idoso fragilizado como missão proporciona sentimentos de gratidão, de reciprocidade e comprometimento entre as gerações. Para Costenaro e Lacerda ${ }^{(19)}$, ter cuidado com alguém ou alguma coisa é um sentimento inerente ao ser humano, ou seja, é natural da espécie humana, pois faz parte da luta pela sobrevivência e também do cotidiano dos cuidadores informais de idosos.

Eu cuido dele com muito amor, carinho, muita dedicação, porQue Quando ele era sadio e trabalhava, tudo que eu pedia ele me dava, então por tudo que ele já fez por mim, eu tenho que fazer por ele, eu vivo praticamente para cuidar dele [...] no mais no meu modo de pensar, a gente tem Que ter muito carinho com ele, a gente tem Que ficar sempre em alerta, QualQuer coisa diferente, a gente pára o Que está fazendo e vai cuidar dele, fazer uma massagem $[\ldots](\mathrm{Cl})$.

Eu tenho esperança, muita fé em Deus, de um dia ele puder levantar e sair andando. Se for a vontade de Deus que ele ande, vou ficar muito feliz, e se não for da vontade de Deus, eu peço Que me dê força, pra mim não me curvar diante das dificuldades e da dor, porque tem dia que eu estou toda dolorida que não pode nem encostar em mim [...] (C3).

Esses discursos estão repletos de valores Que, independentemente do enfoque, priorizam a paz, a liberdade, o respeito, o amor, a dedicação e o zelo. São frutos de um trabalho sensível e humano Que fortalece sentimentos e conserva a relação entre Quem cuida e Quem é cuidado ${ }^{(34)}$, porque "[...] eu vivo praticamente para cuidar dele” (C1), com “[...] muito carinho, maior amor, né!” (C2).

\section{CONSIDERAÇÕES FINAIS}

A interpretação dos discursos dos cuidadores envolvidos nesta pesquisa e a possibilidade de interagir com os autores Que produzem na área foram gratificantes e levaram à elaboração de algumas recomendações.

Visto Que os cuidadores estão em condições de sobrecarga de trabalho e vivenciam situações de conflito em seu ambiente familiar Que contribuem para o seu adoecimento, cabe aos profissionais de saúde propor políticas e implantar programas de suporte social à família, voltados para a realidade desses cuidadores.

Os profissionais de saúde devem oferecer, aos cuidadores, as orientações necessárias ao cuidado, principalmente em relação às pessoas portadoras de doenças crônico-degenerativas de Quem estão cuidando. Devem, ainda, proporcionar atenção à saúde dos cuidadores, considerando Que a atividade de cuidar de um idoso dependente é desgastante e implica riscos à saúde.

Recomenda-se também Que as famílias sejam incentivadas a atuar junto com o cuidador do idoso dependente, dividindo tarefas e procurando proporcionar um clima de satisfação no ambiente familiar.

Os cuidadores de idosos dependentes precisam também do aporte dos profissionais a fim de eue possam dispensar o cuidado adequado e assegurar, a si próprios, satisfatória eualidade de vida.

\section{REFERÊNCIAS}

I. Papaléo NM. Gerontologia: A velhice e o envelhecimento em visão globalizada. São Paulo: Atheneu; 1996.

2. Sanchez MA. A dependência e suas implicações para a perda de autonomia: estudo das representações para idosos de uma unidade ambulatorial geriátrica. Textos Envelhecimento 2000; 3(3).

3. Sena RR, Leite ICA. O ser cuidador na internação domiciliar em Betim/MG. Rev Bras Enferm 2000; 53(4): 544-54.

4. Creutzberg M, Santos BRL. Famílias cuidadoras de pessoa idosa: relação com instituições sociais e de saúde. Rev Bras Enferm 2003; 56(6): 624-9.

5. Santos SMA. O cuidador familiar de idosos com demências: um estudo Qualitativo em famílias de origem nipo-brasileiras. [tese]. Campinas (SP): Universidade Estadual Campinas; 2003.

6. Gonçalves LHT. Conhecendo o familiar cuidador de idosos em domicílio. In: $5^{\circ}$ Congresso Nacional da Rede Unida. 2004; Belo Horizonte (MG), Brasil. Belo Horizonte: EMCD; 2004. p. 242.

7. Ministério da Saúde (BR). Internação Domiciliar no âmbito do SUS. Portaria $\mathrm{n}^{\circ} 2.529$ de 19 de Outubro de 2006. Institui a Internação Domiciliar no âmbito do SUS. Brasília (DF): Ministério da Saúde; 2006.

8. Leal MGS. O desafio da longevidade e o suporte ao cuidador. Terceira Idade 2000; I I (20).

9. Triviños ANS. Introdução à pesQuisa em ciências sociais: a pesQuisa Qualitativa em educação. São Paulo: Atlas; 1994.

10. Minayo MCS. O desafio do conhecimento: pesquisa Qualitativa em saúde. 7ª ed. São Paulo: Hucitec-Abrasco; 2000.

II. Gadotti M. Pedagogia da Práxis. 4a ed. São Paulo: Cortez, 2004.

12. Duarte SF, Furtado MSV. Manual para elaboração de monografias e projetos de pesquisa. $3^{\mathrm{a}}$ ed. Montes Claros: Unimontes; 2002

13. Lakatos EM, Marconi MA. Fundamentos de metodologia científica. $4^{\mathrm{a}}$ ed. São Paulo: São Paulo: Atlas; 2001. 
14. Leopardi MT. Metodologia da pesquisa em saúde. $2^{\text {a }}$ ed. Florianópolis: UFSC; 2002.

15. Elias VC. Mal de Alzheimer: a cor da dor. Caxias do Sul: Edus; 1998.

16. Carvalho Filho ET. Fisiologia do envelhecimento. In: Papaléo NM, Carvalho FET. Geriatria: Fundamentos, clínica e terapêutica. $2^{a}$ ed. São Paulo: Atheneu; 2005. p. 43-62.

17. Duarte YAO. O Processo de envelhecimento e a assistência ao idoso. In: Brasil. Ministério da Saúde. Instituto para o desenvolvimento da saúde: Manual de enfermagem Programa de Saúde da Família. Brasília: Ministério da Saúde; 200l. p. 189-96.

18. Duthie EH. Geriatria prática. $3^{\mathrm{a}}$ ed. Rio de Janeiro: Revinter; 2002.

19. Constenaro RGS, Lacerda MR. Quem cuida de Quem cuida? Quem cuida do cuidador? Santa Maria: Centro Universitário Franciscano; 200I

20. Perline NMOG, Faro ACM. Cuidar de pessoa incapacitada por acidente vascular cerebral no domicílio: o fazer do cuidador familiar. Rev Esc Enferm USP 2005; 39(2): 154-63.

21. Marques B. Quem ama se cuida: Vida e saúde. Costenaro RGS, Lacerda MR, editores. Santa Maria: Centro Universitário Franciscano; 2001. 96p.

22. Araújo MAS, Nakatani AYK, Souza ACS. O conhecimento do agente comunitário na atenção a saúde do idoso. Goiânia: 2005 nov. [citado em 25 jun 2006]. Disponível em: http:// dtr200l saude.gov.br/bvs/publicacoes/57cbe/ resumos/ 1813.htm.

23. Thober E, Creutzber M, Viegas K. Nível de dependência de idosos e cuidados no âmbito hospitalar. Rev Bras Enferm 2005;
58(4): 438-43

24. Elsen I, Marcon SS, Santos MR. O viver em família e sua interface com a saúde e a doença. Maringá: Eduem; 2002.

25. Scazufca M. Impacto nos cuidadores com demência e suas complicações para os serviços de saúde. In: Forlenza OV, Caramelli P. NeuropsiQuiatria geriátrica. São Paulo: Atheneu; 2001. p. 577-85.

26. Alvarez AM. Tendo Que cuidar: a vivência do idoso e sua família cuidadora no processo de cuidar e ser cuidado em contexto domiciliar. Florianópolis: UFSC; 2001.

27. Zimermam Gl. Velhice: Aspectos biopsicosociais. Porto Alegre: Artmed; 2000.

28. Neri AL, Sommerhalder C. As várias faces do cuidado e do bem-estar do cuidador. Neri L, editor. Campinas: Alínea; 2001 .

29. Diogo MJDE, Ceolim MF, Cintra FA. Orientações para idosas Que cuidam de idosos no domicílio. Rev Esc Enferm USP 2004; 39(1): 97-102.

30. Creutzberg M. Tratar mais a pessoa idosa, sobretudo a Que está acamada: subsídios para o cuidado domiciliar. Mundo da Saúde 2000; 24(4): 298-305.

31. Leal MGS. Instituto de desenvolvimento emocional aplicado. [citado 15 out 2005]; Disponível em: http:/ www.unim eds.com.br/conteudo/ME07.htm.

32. Goldstein LL. Stress e coping na vida adulta e na velhice. In: Neri AL. Psicologia do Envelhecimento. Campinas: Papirus; 1995.

33. Boff L. Saber Cuidar: ética humana, compaixão pela terra. $7^{\mathrm{a}}$ ed. Petrópolis: Vozes; 2001. 199p.

34. Waldow VR. Maneiras de cuidar e maneiras de ensinar. Porto Alegre: Artes Médicas; 1995. 